\title{
Interictal regional cerebral blood flow during non specific activation test in partial epilepsy
}

\author{
J VALMIER, J TOUCHON, M BALDY-MOULINIER \\ From Service d'Explorations Fonctionnelles du Systéme Nerveux Central et Périphérique, Hopital Gui de \\ Chauliac, Montpellier, France
}

SUMMARY In order to investigate, during activation testing, the interictal cortical cerebral blood flows (rCBF) of epileptic patients suffering from complex partial seizures, 40 epileptic patients (divided into "lesional", this is, with abnormal CT findings, and "non lesional", that is, with normal CT findings) were submitted to rCBF measurements with the 133 xenon intravenous technique, at rest and during intermittent light stimulation (ILS). The findings compared with normal volunteers seem to demonstrate that, during ILS, (1) in non lesional patients, the suspected epileptic focus shows a significant rCBF increase (2) in lesional patients, the significant $\mathrm{rCBF}$ increases were not in the region of the suspected epileptic focus but in adjacent or in contralateral ones. It was concluded that activation interictal rCBF measurements are more useful than resting ones for the determination of epileptic foci when CT findings are normal and that the nature of the epileptic focus influences markedly the interhemispheric activation pattern.

The haemodynamic and metabolic patterns of patients suffering from partial seizures are now well documented. During the ictal state, the epileptic focus is characterised by a local increase of regional cerebral blood flow $(\mathrm{CBF})^{12}$ and metabolism. ${ }^{3-9}$ During resting interictal measurements, the electroencephalographic (EEG) epileptic focus shows a concomitant decrease in metabolism $^{4-9}$ and $\mathrm{rCBF}^{-15}$ This decrease often extends beyond the region of the EEG epileptic focus to other cortical ${ }^{81316}$ and subcortical areas $^{4617}$ and depends on clinical ${ }^{18}$ and therapeutic ${ }^{19} 20$ parameters.

However, little is known, in the interictal period, about the rCBF pattern of patients suffering from partial complex seizures during specific activation testing. It is of clinical and physiological interest to answer the following question: Does the region of resting interictal $\mathrm{rCBF}$ decrease and hypometabolism show a reduced, normal or increased reactivity during functional activation? Few studies deal with the subject and none are conclusive about rCBF activation. Studying epileptic subjects with normal CT scans, Sakai et al $^{21}$ found inconsistent rCBF patterns: during activation, some of the patients showed a rCBF

\footnotetext{
Address for reprint requests: Dc J Valmier, Service d'Explorations Fonctionnelles du Systéme Nerveux Central et Périphérique, Hopital Gui de Chauliac, 34059 Montpellier, France.
}

Received 22 July 1988.

Accepted 8 August 1988


epileptic focus while others had a rCBF decrease in comparison with the resting state. In five patients, Hougaard $e t a l^{2}$ described hyperactivity of the epilep-o tic focus during photic stimulation but only one hemisphere was analysed and two patients had brain tumours.

Assuming that these heterogeneous results are due to the selected populations (with or without macroscopic lesions) and to the activity of the epileptic focus (ictal/interictal), the aim of our study was to analyse the cortical CBF changes that occur during activation testing, in patients suffering from complex partial seizures in comparison with a control group (normal volunteers). The xenon 133 intraveneous injection method was utilised. The activation test used was intermittent light stimulation (ILS).

\section{Subjects and methods}

Fifty subjects were selected: $\mathbf{4 0}$ were epileptic patients with complex partial seizures and 10 were normal volunteers.

In accordance with the international classification, ${ }^{22}$ all the 40 epileptic patients had clinically characterised complex partial seizures. Using CT data and neurological examination, two groups were differentiated:

(1) Group 1 included 27 patients with normal CT scans (cases 1 to 27 ; 14 females, 13 males; mean age: $27 \cdot 3$ years, range 13 58 years). All were neurologically normal on examination. Some individual clinical features are shown in table 1 . The 
Table 1 Clinical, CT and rCBF data of the "non lesional" epileptic patients (Group 1)

\begin{tabular}{|c|c|c|c|c|c|c|c|c|c|}
\hline $\begin{array}{l}\text { Subject/ } \\
\text { Sex/Age } \\
(y r)\end{array}$ & $\begin{array}{l}\text { Onset of } \\
\text { seizures } \\
(y r)\end{array}$ & Drugs & $\begin{array}{l}\text { Focus } \\
\text { state }\end{array}$ & $\begin{array}{l}\text { Site of } \\
\text { EEG } \\
\text { abnormalities }\end{array}$ & $\begin{array}{l}\text { Site of } \\
C T \text { scan } \\
\text { abnormalities }\end{array}$ & $\begin{array}{l}\text { Site of } \\
\text { rest } \\
\text { hypoperfusion }\end{array}$ & $\begin{array}{l}\text { Site of } \\
\text { rCBF } \\
\text { hypereactivity }\end{array}$ & $\begin{array}{l}\text { Site of } \\
\text { rCBF } \\
\text { hyporeactivity }\end{array}$ & $\begin{array}{l}\text { Significant } \\
\text { asymmetries }\end{array}$ \\
\hline 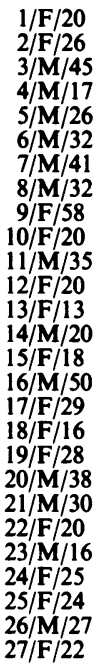 & $\begin{array}{r}14 \\
7 \\
44 \\
2 \\
12 \\
3 \\
30 \\
12 \\
54 \\
1 \\
33 \\
2 \\
12 \\
13 \\
16 \\
46 \\
12 \\
15 \\
25 \\
7 \\
12 \\
19 \\
16 \\
12 \\
12 \\
15 \\
14\end{array}$ & $\begin{array}{l}\text { CBZ } \\
\text { CBZ, PHT } \\
- \text { CBZ, P } \\
\text { CBZ,P } \\
\text { P } \\
\text { VPA } \\
\text { VPA, P } \\
\text { VPA } \\
\text { CBZ } \\
\text { CBZ } \\
\text { CBZ, P } \\
\text { P } \\
\text { P } \\
\text { P } \\
\text { CBZ } \\
\text { CBZ } \\
\text { CBZ } \\
\text { CBZ, P } \\
\text { CBZ } \\
- \\
- \\
\text { CBZ, VPA } \\
\text { CBZ, VPA } \\
\text { CBZ } \\
\text { CBZ }\end{array}$ & $\begin{array}{l}\text { I } \\
\text { I } \\
\text { I } \\
\text { I } \\
\text { I } \\
\text { I } \\
\text { I } \\
\text { I } \\
\text { I } \\
\text { I } \\
\text { I } \\
\text { I } \\
\text { I } \\
\text { I } \\
\text { I } \\
\text { I } \\
\text { I } \\
\text { I } \\
\text { I } \\
\text { I } \\
\text { I } \\
\text { I } \\
\text { I } \\
\text { I } \\
\text { I } \\
\text { S } \\
\text { S }\end{array}$ & $\begin{array}{l}\text { LT } \\
\text { LT } \\
\text { LT } \\
\text { RTF } \\
\text { RT } \\
\text { LT } \\
\text { LTF } \\
\text { LT } \\
\text { RTO } \\
\text { LT } \\
\text { LT } \\
\text { LT } \\
\text { RT } \\
\text { LTF } \\
\text { LT } \\
\text { RT } \\
\text { LT } \\
\text { RT } \\
\text { RT } \\
\text { BiF } L>\text { R } \\
\text { BiT } ~ \\
\text { BiT } \\
\text { BiF } \\
\text { BiT } \\
\text { BiT } \\
\text { RT } \\
\text { RT }\end{array}$ & $\begin{array}{l}\text { None } \\
\text { None } \\
\text { None } \\
\text { None } \\
\text { None } \\
\text { None } \\
\text { None } \\
\text { None } \\
\text { None } \\
\text { None } \\
\text { None } \\
\text { None } \\
\text { None } \\
\text { None } \\
\text { None } \\
\text { None } \\
\text { None } \\
\text { None } \\
\text { None } \\
\text { None } \\
\text { None } \\
\text { None } \\
\text { None } \\
\text { None } \\
\text { None } \\
\text { None } \\
\text { None }\end{array}$ & $\begin{array}{l}\overline{\text { LT }} \\
\text { LF } \\
\text { RT } \\
\text { RF } \\
- \\
\overline{\text { LF }} \\
\text { RTF } \\
\text { LT } \\
\text { RTF } \\
\text { RF } \\
\text { RF } \\
- \\
- \\
- \\
- \\
\overline{-} \\
\overline{-} \\
\overline{-} \\
\text { LT } \\
\overline{-} \\
\overline{\text { BiT Increase }} \\
\text { RT Increase }\end{array}$ & $\begin{array}{l}\text { LT } \\
\text { LT } \\
\text { LT, BiF } \\
\text { RTF } \\
\text { RT, LF } \\
\text { LT } \\
\text { LF } \\
\text { LTO } \\
\text { RT } \\
\text { LT } \\
\text { RTF } \\
\text { RF } \\
\text { RF } \\
= \\
= \\
- \\
- \\
- \\
- \\
= \\
\overline{-} \\
\text { RT } \\
= \\
-\end{array}$ & $\begin{array}{l}\text { LF } \\
\text { RT } \\
\text { RT } \\
\text { LF } \\
\text { LT } \\
- \\
\ddot{\text { RT }} \\
- \\
\overline{\text { LT }} \\
= \\
\overline{\text { RT }} \\
\text { LF } \\
\text { LT } \\
= \\
= \\
\overline{\text { RF }} \\
\text { RTO } \\
\text { LTO } \\
\text { LT } \\
\text { LT } \\
\text { RT } \\
-\end{array}$ & $\begin{array}{l}\text { LT > RT } \\
\text { LT > RT } \\
\text { LT > RT } \\
\text { RTF > LTF } \\
\text { RT > LT } \\
\text { LT > RT } \\
\text { LF > RF } \\
\text { LT > RT } \\
\text { RT > LT } \\
\text { LTF > RTF } \\
\text { RTF > LTF } \\
- \\
\overline{\text { LT }}>\text { RT } \\
\text { LT > RT } \\
\text { RT > LT } \\
- \\
- \\
\overline{\text { LF }}>\text { RF } \\
\text { LTO > RTO } \\
\text { RTO > LTO } \\
\text { RT > LT } \\
\text { RT > LT } \\
- \\
-\end{array}$ \\
\hline
\end{tabular}

I = interictal state; $\mathbf{S}=$ subictal state; $\mathbf{C B Z}=$ Carbamazepine; $P H T=$ phenytoine; $\mathbf{P}=$ phenobarbital; VPA = sodium valproate; $F=$ frontal region; $T=$ temporal region; $P=$ parietal region; $O=$ occipital region; $R=$ right; $L=$ left, Only significant $r C B F$ data (see methods) was noted,

aetiology was unknown in most; five patients had had perinatal insult, four had had febrile convulsions in childhood and a history of epilepsy was found in the families of three patients.

(2) Group 2 included 13 subjects (cases 28 to 40) with abnormal CT scans except cases 28 and 31 which did not have CT performed but a history of right partial temporal lobectomy (one for abscess and one for haematoma) (table 2). None had non progressive lesions and the onset of the seizures was after the development of the lesion. Three had non regressive perinatal or childhood insult, five had surgical lobectomy, three had had head injuries and two cerebrovascular diseases.
The EEG patterns of each patient were studied by repeated standard EEG recordings and by one or more all night polygraphic recordings. None of the patients were photosensitive during ILS. The lateralisation of the epileptic abnormalities was determined according to the following criteria: (1) the localisations of epileptic abnormalities during the interictal state and during the onset of the seizures $(70 \%$ of the patients) and (2) the stability of interictal epileptic abnormalities during the three states of alertness: wakefulness, NREM sleep, REM sleep. For greater accuracy, the EEG findings were compared with clinical lateralisation data during seizures and interictal lateralised rCBF hypoperfusion when these data were available. The criteria were satisfied for

Table 2 Clinical, CT and rCBF data of the "lesional" epileptic patients (Group 2). See legends in Table 1.

\begin{tabular}{|c|c|c|c|c|c|c|c|c|c|}
\hline $\begin{array}{l}\text { Subject/ } \\
\text { Sex/Age } \\
(y r)\end{array}$ & $\begin{array}{l}\text { Onset of } \\
\text { Seizures } \\
(y r)\end{array}$ & Drugs & $\begin{array}{l}\text { Focus } \\
\text { state }\end{array}$ & $\begin{array}{l}\text { Site of } \\
\text { EEG } \\
\text { abnormalities }\end{array}$ & $\begin{array}{l}\text { Site of } \\
\text { CT scan } \\
\text { abnormalities }\end{array}$ & $\begin{array}{l}\text { Site of } \\
\text { rest } \\
\text { hypoperfusion }\end{array}$ & $\begin{array}{l}\text { Site of } \\
\text { rCBF } \\
\text { hypereactivity }\end{array}$ & $\begin{array}{l}\text { Site of } \\
\text { rCBF } \\
\text { hyporeactivity }\end{array}$ & $\begin{array}{l}\text { Significant } \\
\text { asymmetries }\end{array}$ \\
\hline $\begin{array}{l}28 / \mathrm{M} / 29 \\
29 / \mathrm{F} / 26 \\
30 / \mathrm{F} / 30 \\
31 / \mathrm{M} / 33 \\
32 / \mathrm{M} / 22 \\
33 / \mathrm{F} / 34 \\
34 / \mathrm{M} / 65 \\
35 / \mathrm{M} / 21 \\
36 / \mathrm{M} / 20 \\
37 / \mathbf{F} / 23 \\
38 / \mathbf{M} / 40 \\
39 / \mathbf{F} / 14 \\
40 / \mathbf{M} / 33\end{array}$ & $\begin{array}{r}28 \\
6 \\
27 \\
30 \\
31 \\
29 \\
4 \\
4 \\
5 \\
25 \\
10 \\
2 \\
21\end{array}$ & $\begin{array}{l}\text { P } \\
\text { VPA, P } \\
\text { VPA } \\
- \text { VPA, P } \\
\text { VFA } \\
\text { PHT, P } \\
\text { VPA } \\
\text { VPA, P } \\
\text { VPA, P } \\
\text { VPA, P } \\
\text { CBZ } \\
\text { VPA, P }\end{array}$ & $\begin{array}{l}\text { I } \\
\text { I } \\
\text { I } \\
\text { I } \\
\text { I } \\
\text { I } \\
\text { I } \\
\text { I } \\
\text { I } \\
\text { I } \\
\text { S } \\
\text { S } \\
\text { ictal }\end{array}$ & $\begin{array}{l}\text { BiF R > L } \\
\text { BiT R }>\text { L } \\
\text { RFT } \\
\overline{\text { BiF } R>L} \\
\text { L slow waves } \\
\text { RT } \\
\text { LT } \\
\text { BiFT } \\
\overline{\text { BiT }} \\
\overline{\text { LF }}\end{array}$ & $\begin{array}{l}\text { Not done } \\
\text { RT } \\
\text { RT } \\
\text { Not done } \\
\text { RF } \\
\text { LH, LT + } \\
\text { RTF } \\
\text { LP } \\
\text { RF } \\
\text { LTP } \\
\text { LTO } \\
\text { LTF } \\
\text { LF }\end{array}$ & $\begin{array}{l}\text { RT } \\
\text { RT } \\
\text { RT } \\
\text { RT } \\
\text { RTF } \\
\text { LP } \\
\text { RTF } \\
\text { RT } \\
\text { LF } \\
\text { RT Increase } \\
\text { RT Increase } \\
\text { LPF Increase } \\
\text { RTF } \\
\text { Decrease }\end{array}$ & $\begin{array}{l}\text { RTF } \\
\text { LT } \\
\text { RP } \\
\text { RPO, LO } \\
\text { LTF } \\
\text { LP, RTP } \\
\text { RTPO, LTF } \\
\text { RTP } \\
\text { LF } \\
\text { RP } \\
\text { LO } \\
\text { LP }\end{array}$ & $\begin{array}{l}\text { LTFP } \\
- \\
\overline{\text { RTP, LF }} \\
\overline{\text { LF, RF }} \\
\text { RF } \\
- \\
\overline{\text { LH }} \\
\text { RT } \\
\text { RT } \\
\text { LF }\end{array}$ & $\begin{array}{l}\text { RTFP > LTFP } \\
\text { LT > RT } \\
\text { RP > LP, LT > RT } \\
\text { RFPO > LPFO, LT > RT } \\
\text { LTF > RTF } \\
\text { RTF > LTF } \\
\text { LFT > RFT, RPO > LPO } \\
\text { RT > LT } \\
\overline{\text { RH }>\text { LH }} \\
\overline{\text { LT }>\text { RT }} \\
\text { RF }>\text { LF }\end{array}$ \\
\hline
\end{tabular}


all the Group 1 patients except cases 11 and 12, which showed opposite EEG and CBF results. For these two cases, the hypoperfusion area was considered as the epileptic focus because four repeated measurements showed an increase during the ictal state and a decrease during the interictal period in this region, each rCBF measurement separated by at least one month.

The anticonvulsive therapy remained unchanged for the month preceding the study. Pertinent therapeutic data are given in table 2 . For the patients tested, drug plasma levels were in the normal ranges.

The epileptic patients were considered to be in the interictal state when they had been free of seizure for 2 days before and after rCBF measurements and the seizure frequency was unchanged for the month preceding the study.

Ten normal volunteers (Control Group) with no history of neurological disease, normal neurological examination and receiving no drugs were examined using the I.V. 133 xenon clearance technique in order to determine rCBF control values (mean age: $27 \cdot 2$, range 22-33 years). Four were females, six were males.

rCBF was measured by the 133 xenon intravenous technique using a multidetector system (Mecaserto) as described in Valmier et al. ${ }^{18}$ The tracer $(15 \mathrm{mCi})$ was injected intravenously in a bolus. The arterial blood pressure was measured before and after each measurement. The $\mathrm{CO}_{2}$ arterial partial pressure $\left(\mathrm{PaCO}_{2}\right)$ was analysed during the 13 minutes of the data acquisitions with a DATEX capnograph. During rest measurements, the subjects were required to lie down with eyes closed, in silence. During the activation testing, ILS was performed 30 seconds before the onset of the acquisition and stopped 6 minutes after. The frequency was $15 \mathrm{~Hz}$.

rCBF was computed using a two compartimental analysis for the clearence curve allowing a correction for xenon recirculation based on the end-tidal tracer concentration. ${ }^{23}$ The study of rCBF was limited to F1 derivated from the initial slope of the clearence curve and considered as greymatter flow. Twelve sodium iodide crystal scintillation detectors were placed symmetrically over each hemisphere.

In order to analyse rCBF variations between resting and activated states, three sets of parameters were determined: (1) the percentage of variation between rest and activation:

$$
\frac{\mathbf{R s}-\mathbf{R r}}{\mathbf{R r}} \times 100
$$

where $R r$ and $R s$ are the respective absolute $\mathrm{rCBF}$ values at rest and during activation testing.

(2) the normalised variation between rest and activation (Activation Index):

$$
\frac{\mathrm{Rs}-\mathrm{Rr}}{\mathrm{Hs}+\mathrm{Hr}} \times 100
$$

where $\mathrm{Rr}$ and $\mathrm{Rs}$ correspond to those of the first equation and $\mathrm{Hr}$ and $\mathrm{Hs}$ are calculated from the average mean of the right and the left hemisphere at rest and in the stimulated state respectively $(\mathrm{Rr} / \mathrm{Hr}=$ resting ratio, $\mathrm{Rs} / \mathrm{Hs}=$ activation ratio).

(3) the asymmetry variation between rest and activation (Asymmetry Index):

$$
\frac{\mathrm{Rs}-\mathrm{Rr}}{\mathrm{Ls}+\mathrm{Lr}} \times 100
$$

where $R$ and $L$ are the right and left homologous region at rest (r) and in the activated state (s).

Statistical analysis: Initially, the Control Group was analysed by selecting four regions of interest on each hemiphere: the frontal (F) (4 detectors), the temporal (T) (2 detectors), the parietal (P) (3 detectors) and the occipital regions (O) (1 detector). The sensory-motor (central) area was not considered as a region of interest. rCBF values were normally distributed (chi square test). Variance analysis (ANOVA) was used to determine whether changes between the resting and the stimulated state were significant for this group.

Subsequently, from the 20 local, eight regional and two hemispheric values, normal variations for each rCBF parameter (equations 1, 2, 3) were calculated as follows:

$$
\mathbf{M}-(2 \mathrm{SD})<\text { normal values < } \mathrm{M}+(2 \mathrm{SD})
$$

where $M$ represents the mean and SD the standard deviation of the same parameter for the Control Group. For the epileptic patients, local, regional and hemispheric CBF values were analysed and when the relative $\mathrm{CCBF}$ parameter values were not included in these two ranges, they were considered as abnormal.

\section{Results}

\section{Normal subjects (Control Group)}

There was a global but not significant $\mathrm{rCBF}$ increase $\mathrm{\omega}$ $(8 \%$, SD $13.9 \%)$ during photic stimulation. Table 3 summarise the values of the different indices.

A four (lobes) by two (conditions) ANOVA with repeated measures on all two factors was performed This yielded an effect for lobes $(F=9 \cdot 10 ; p<0.001)$ reflecting a general anterior-to-posterior resting gradient (fig 1a). The ANOVA yielded also condition by lobes interaction $(F=4.32 ; p<0.001)$. Test for simple main effects showed that the conditions differed significantly for the left temporo-parieto-occipital regions and for the right parieto-occipital regions, reflecting a posterior-to-anterior activation gradient (fig 1b).

\section{Epileptic patients with normal CT scans (Group 1)} Interictal measurements: There were no global CBF variations between the resting and the stimulated state $(1.8 \%$, SD $3.6 \%)$. Twenty one of 25 epileptic patients showed an abnormal rCBF pattern during photic stimulation (table 1). For 16 (cases 1-16) of 19 epileptic patients with stable EEG epileptic focus (cases 1-19), an activation index increase and/or a greater asymmetries was observed in the suspected epileptic focus: one subject (case 13) showed only a rCBF activation in the region corresponding to resting hypoperfusion and epileptic EEG abnormalities, three patients (cases 14, 15, 16) demonstrated only an asymmetry greater for the epileptic region than the homologous contralateral one and the 12 others showed both an activation and a greater asymmetry in the region of the stable epileptic focus. Moreover eight 
Table 3 rCBF pattern of the Control Group at rest and during intermittent light stimulation

\begin{tabular}{|c|c|c|c|c|}
\hline & Resting ratio (SD) & $\%$ of $r C B F$ increase (SD) & Activation index (SD) & Asymmetry index (SD) \\
\hline \multirow{2}{*}{$\begin{array}{l}\text { LEFT } \\
\text { HEMISPHERE } \\
\text { RIGHT }\end{array}$} & $0.5(2)$ & $7 \cdot 2(14 \cdot 8)$ & $-0.9(2.8)$ & \multirow{2}{*}{$1 \cdot 7(5 \cdot 6)$} \\
\hline & $-0.5(2)$ & $8.9(13.2)$ & $0.9(2.8)$ & \\
\hline \multirow{2}{*}{$\begin{array}{l}\text { LEFT } \\
\text { FRONTAL } \\
\text { RIGHT }\end{array}$} & $6 \cdot 6(3 \cdot 6)$ & $3.4(14.8)$ & $-4 \cdot 8(4)$ & \multirow{2}{*}{$3 \cdot 2(5 \cdot 3)$} \\
\hline & $5 \cdot 8(4 \cdot 4)$ & $6 \cdot 7(14 \cdot 4)$ & $-1.4(3.6)$ & \\
\hline \multirow{2}{*}{$\begin{array}{l}\text { LEFT } \\
\text { TEMPORAL } \\
\text { RIGHT }\end{array}$} & $-2 \cdot 7(6)$ & $6 \cdot 6(13 \cdot 3)$ & $-1.4(7.8)$ & \multirow{2}{*}{$2 \cdot 7(9 \cdot 3)$} \\
\hline & $-4(3 \cdot 7)$ & $9 \cdot 3(13)$ & $1.4(7)$ & \\
\hline \multirow{2}{*}{$\begin{array}{l}\text { LEFT } \\
\text { PARIETAL } \\
\text { RIGHT }\end{array}$} & $-5 \cdot 2(7 \cdot 1)$ & $14 \cdot 3(13.9)$ & $5 \cdot 2(7 \cdot 9)$ & \multirow{2}{*}{$-2 \cdot 7(6 \cdot 1)$} \\
\hline & $-6 \cdot 4(8)$ & $11 \cdot 6(16 \cdot 6)$ & $2 \cdot 3(6 \cdot 1)$ & \\
\hline \multirow{2}{*}{$\begin{array}{l}\text { LEFT } \\
\text { OCCIPITAL } \\
\text { RIGHT }\end{array}$} & $-9 \cdot 4(7 \cdot 1)$ & $18 \cdot 8(20 \cdot 6)$ & $7 \cdot 86(9.8)$ & \multirow{2}{*}{$-0.83(15.1)$} \\
\hline & $-6 \cdot 1(5 \cdot 7)$ & $18 \cdot 1(21 \cdot 1)$ & $7 \cdot 29(10 \cdot 2)$ & \\
\hline
\end{tabular}

Values (means, SD) of the different rCBF indexes (see methods) for the Control Group $(n=10)$.

had a significant activation index decrease in the region contralateral to the EEG abnormalities. For all the patients with a unilateral epileptic focus, the comparison of the activation index mean values between the suspected epileptic focus region $(6.7 \%$, SD $7.9 \%)$ and the contralateral one $(-4 \%$, SD $5 \%)$ is shown in fig 2. Considering the other six patients with bilateral epileptic EEG abnormalities (cases 20-25), five had abnormal rCBF index values. All five showed significant regional asymmetries and a lower activation index in the contralateral areas of the greater asymmetry. Case 24 also had an increased activation

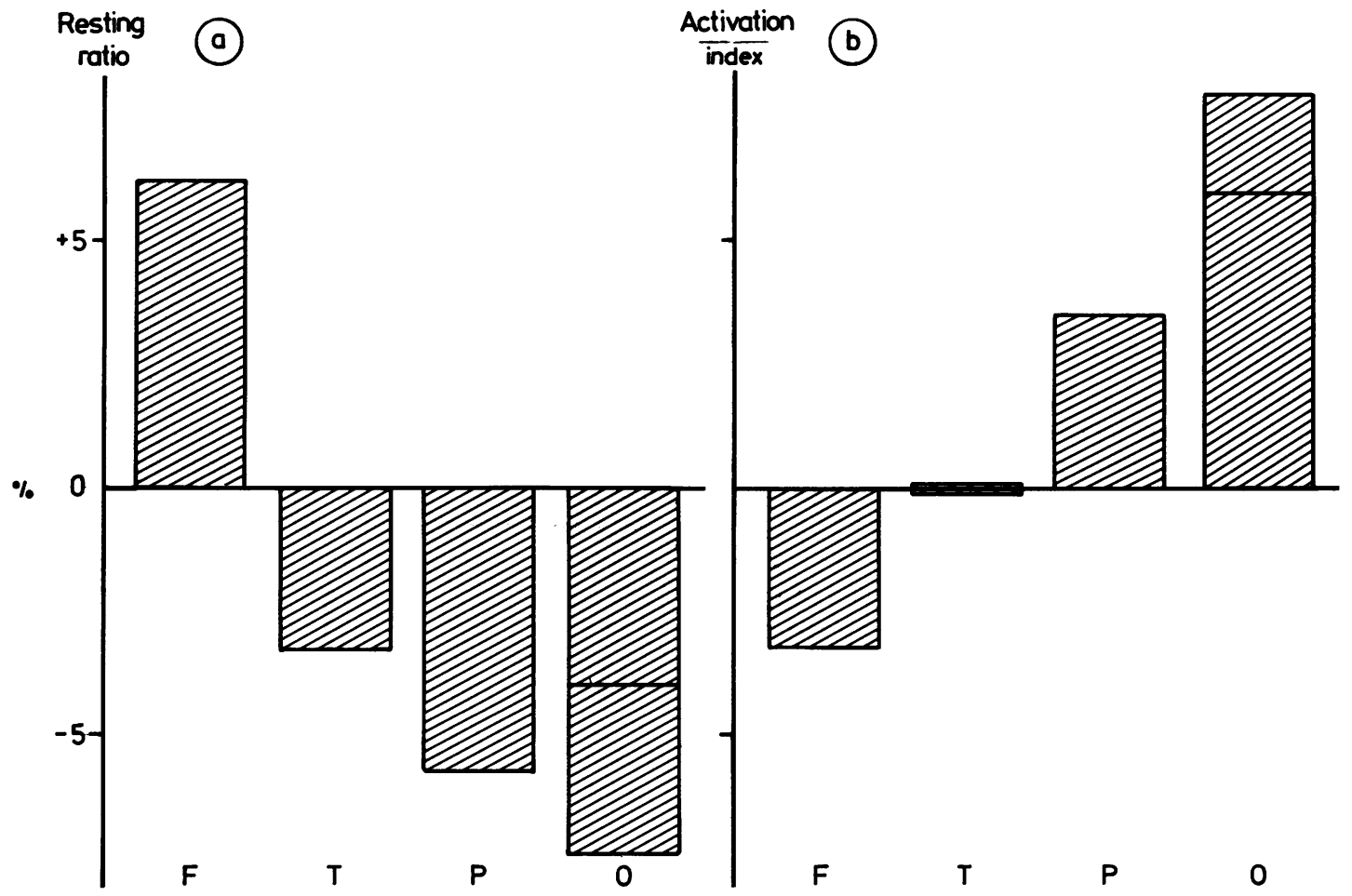

Fig 1 (a) $r C B F$ resting ratio values of the control group $(N=10)$. (b) $r C B F$ activation index values of the control group $(N=10) . F=$ frontal region; $T=$ temporal region; $P=$ parietal region; $O=$ occipital region. Means, $S D$ are from table 3. 




Fig 2 Controlateral (CF) and epileptic focus $(F)$ activation index for the "non lesional" (Group 1) $(N=19)$ and the "lesional" (Group 2) ( $N=10)$ epileptic patients. Means, $S D$ are from the Results section. ${ }^{*} p<0.01$ between epileptic regions and controlateral ones ( $t$ tailed test).

index in the region corresponding to the site of the greater asymmetry. Two of the cases (nos 21 and 22) showed greater asymmetry in the region corresponding to the predominant EEG epileptic focus and the decrease of the activation index in the opposite region. Subictal measurements: Case 26 had one complex partial seizure 2 hours before the rCBF measurements. The resting data showed a bitemporal CBF increase. During ILS the right temporal region corresponding to the unilateral EEG focus exhibited a decrease of the activation index. Case 27 with right EEG focus had a seizure frequency increase 2 weeks before. She had a seizure 3 hours before the rCBF measurements. The resting rCBF pattern showed a right temporal flow increase while the stimulated one demonstrated no activation pattern.

Epileptic patients with abnormal CT scans (Group 2) Interictal measurements: The interictal results are summarised in table 2 . There was a slightly but not significant global CBF decrease (- $4.9 \%$, SD $3 \cdot 1 \%)$ during photic stimulation in comparison to the resting state. Five of the 10 patients showed an activation index increase in part and around regions of resting interictal rCBF and CT scan abnormalities. Furthermore, for the five others, it was a region contralateral to the lesional hemisphere that showed the greater rCBF activation. In nine epileptic patients with abnormal asymmetry index, one (case 28 ) had only a greater asymmetry in the region of the macroscopic lesion while five of them (cases 29, 32, 33, 35, 37) demonstrated a greater asymmetry in the contralateral hemisphere. The three other patients showed a more complex pattern of bilateral significant asymmetries. For the eight patients with complete CT scan data, the means of the activation index values for the macroscopic lesional regions (-3.1\%, SD 5.5\%) and the contralateral ones $(3.9 \%$, SD $6.8 \%)$ showed an inversed non significant $\mathrm{rCBF}$ pattern when compared with Group 1 (fig 2).

Subictal measurements: rCBF measurements for three patients of Group 2 were performed out of the interictal state. They showed a variety of rCBF activation patterns. Case 39 had a greater asymmetry index in the region of macroscopic lesion than in the contralateral one during activation and case 38 showed a significant activation index increase in the lesional area. For both, a decrease of the activation index was seen in the region of resting hyperaemia located in the contralateral hemisphere to the lesion. Case 40 was in ictal state during both rCBF measurements. The patient developed a seizure with clonic movements in the right hand. The resting rCBF study showed a flow increase in the left frontal lesional region and in the left sensory-motor areas. During intermittent light stimulation, an activation index increase was observed in sensory-motor area but there was no activation index increase in the left frontal region.

\section{Discussion}

The findings of this study seem to demonstrate that during activation testing, epileptic patients without a macroscopic lesion show different interictal cortical CBF responses from those obtained from control subjects and epileptic patients with macroscopic lesions.

Confirming previous studies, the control group showed the greater rCBF increase in occipital regions during visual activation testing ${ }^{24}$ and showed an inverse $\mathrm{rCBF}$ pattern (posterior to anterior activation gradient) in comparison with resting state (anterior to posterior resting gradient). ${ }^{25}$ Furthermore, while continous white light stimulation resulted in significant occipital flow increase, intermittent light stimulation caused a maximal occipital increase which was also significant in other cerebral areas, progressively lessening from occipital to frontal regions. This rCBF pattern may be compared with the cortical occipitoparietal synchronisation in EEG studies. ${ }^{26}$

Patients with a stable epileptic focus and no macroscopic lesion showed, during interictal photic stimulation, the maximal activation in the suspected focus region independently of its localisation. Even when the 
resting hypoperfusion and the EEG data localised the epileptic focus in fronto-temporal regions (case 11), not activated by intermittent light stimulation in controls, occipital areas (normally the ones most stimulated) had a smaller rCBF activation than the focus region. These results seem to demonstrate a rCBF increase prevalence in the epileptic focus ("epileptic effect") during interictal photic stimulation upon the others cortical regions. Considering these data and our subictal $\mathrm{rCBF}$ result (that showed a variety of $\mathrm{rCBF}$ patterns during activation testing, more often a $\mathrm{rCBF}$ decrease in the region of resting hyperaemia) the apparent heterogeneity of Sakai's results can be understood. In this latter study, of eight patients who failed to show rCBF activation increase, six had a resting hyperaemic region (suggestive of a subictal state) while of nine patients with increase in flow during activation testing, none had regional hyperaemia during resting state (resembling our interictal state). These two results along with those of Hougaard ${ }^{2}$ seem to demonstrate that epileptic patients suffering from partial seizures have abnormal rCBF patterns during stimulation that fluctuate according to the state of the focus. From this point of view, as Hougaard ${ }^{2}$ suggested it is interesting to consider two states between clinical seizures to describe the epileptic focus: the "subictal" and the "interictal" states, that differ, as shown by this study, both at rest and during functional activation.

Considering that interictal $\mathrm{rCBF}$ and metabolic measurements at rest can localise the suspected region of the epileptic focus in approximately $55 \%$ (ref 12 and the above results) to $70 \%$ of the epileptic patients, ${ }^{78}$ such activation testing may be useful in improving the accuracy of the cortical lateralisation of the focus. In this respect, of six patients with bilateral EEG focii, five showed a lateralised $\mathrm{rCBF}$ activation response when only one had a resting interictal hypoperfusion. With regard to the above observations, the rCBF prevalence of the epileptic focus during interictal activation should be considered as relative to the other regions. It is the interregional prevalence distribution (index values) that is evaluated and compared between patients and controls but not the absolute values which often appear to be greater in normal volunteers when compared with the homologous ones in epileptic patients (see the values of the hemispheric activation index for each group in the result section).

Epileptic patients with macroscopic lesions seem to differ during interictal photic activation from those of the Group 1 on two points: (1) they have a tendency to exhibit a greater activation and/or asymmetries index $(70 \%)$ in the surrounding regions if not in the contralateral ones than in the lesional areas (2) the region contralateral to the macroscopic lesion showed greater asymmetry index than the homolateral one (fig 2).
Ingvar and Risberg, ${ }^{27}$ in non epileptic patients with diffuse cortical macroscopic lesions, found "an increase in rCBF during the test outside the pathologic area, but usually only a slight increase, or a diminution inside it". This "rCBF lesional activation pattern" in patients with unilateral macroscopic lesion and without epilepsy has also been reported..$^{28} 29$

Furthermore, in this study the "rCBF lesion effect" was not the only feature of the patients of Group 2 . Indeed all the patients showed an interictal rCBF activation similar to the "epileptic effect" of the Group 1 but without the same systematisation. In the region of macroscopic lesion Case 28 showed a significant activation during photic stimulation. Cases 30, 31, 33, 34 showed an increase of the activation in region surrounding CT scan abnormalities while the others exhibited a contralateral activation increase. These discrepancies may be considered as resulting from the heterogeneity of the patients who differed in the appearance and the nature of their aetiological factors, as well as the size and the topography of the lesion, parameters that cannot be easily matched. Oikawa and $\mathrm{Kanaya}^{30}$ also found in epileptic patients with non progressive macroscopic lesions that "increased rCBF with photic stimulation was elictied on the anterior and/or posterior border zone of the affected portions" but they could not analyse and compare interhemispheric rCBF patterns with the intracarotid method used as it was possible in this study.

The above results indicate the relationship between rCBF results, the state of the focus and the features of the macroscopic lesions. Other extraneous factors should be considered such as drugs, clinical parameters and methodological factors. It has been demonstrated that some anticonvulsive drugs influence epileptic rCBF. ${ }^{19}{ }^{20}$ However, these drugs involve global CBF changes and cannot explain regional flow abnormalities. Moreover, the rCBF prevalence of the epileptic focus during activation testing was uniform in Group 1, although the anticonvulsive drugs were different and four patients were not receiving therapy. Similarly Groups 1 and 2 showed a tendency to inverse rCBF pattern when the two groups were under anticonvulsive therapy. Thus, if any drug influence exists because it modifies absolute but not relative index values, it is of no importance in the interpretation of the results. In the same manner, if $\mathrm{PaCO}_{2}$ interferes with absolute rCBF variations, it has no influence upon rCBF index (see equations (2) and (3)). On the other hand, individual clinical features such as the onset and the duration of the disease, the sex and the age of the patient, do not seem to interfere with the results because the comparison of the extremes in Group 1 showed the same rCBF pattern (see table 1). Finally, even though the bidimensional xenon 133 method does not allow measurement of 
subcortical epileptic localisation, the demonstration of such abnormal patterns does not appear to be due to artefacts or other sources of false negatives. Our bidimensional resting results are concordant with those of the three dimensional methods ${ }^{4681214}$ and no divergent activation results were obtained with epileptic patients without macroscopic lesions. In the patients with temporal lesions, resting rCBF results are well correlated with CT scans data.

The activation of the suspected epileptic focus during ILS should be considered as a functional feature attributable to the epileptic context, since interference by extraneous parameters are of no importance. Therefore these findings provide additional data concerning the physiopathological question of the nature (lesional and/or functional) of such abnormalities. On a structural basis, the negative CT scan of Group 1 does not exclude microscopic temporo-mesial lesions as observed by several authors. ${ }^{911}$ On the other hand, the proof of a rCBF and metabolic decrease during the resting interictal state, in distant areas from the epileptic focus ${ }^{415}$ and the influence of clinical parameters in the degree and the extent of the resting hypoperfusion ${ }^{18}$ underline the functional aspect of the rCBF pattern of the epileptic brain. From a functional point of view, using the experimental kindling model, Lerner-Natoli et $a l^{32}$ have shown a hypoperfusion and a hypometabolism in the interictal state. But this experimental model of epilepsy is known to have no ultrastructual abnormalities. ${ }^{334}$ The above findings afford two additonal arguments for the existence of secondary functional mechanisms underlying the cortical haemodynamic pattern of the epileptic focus: (1) the significant activation ("hyperactivation") of the suspected epileptic area and (2) that differ from the classical lesion effect.

The above findings raise another question about the nature of the mechanisms involved in the epileptic process. It seems that, in Group 1, the cortical region corresponding to the EEG focus is "hyperfunctional", more so in comparison with the other ones as if some "facilitation" or "excitation" mechanism were present. Such mechanisms are very difficult to interpret. Indeed resting interictal hypoperfusion and hypometabolism of the epileptic focus are in favour of inhibitory mechanisms rather than excitatory ones. On the other hand, the present results show an activation of the suspected epileptic focus when the rCBF variations were compared with index (relative data) but this pattern did not appear in comparison with control absolute data. Therefore it is an apparent hyperfunction resulting from changes in regional interactions rather than a real hyperfunction. It might be an inhibition of some other ipsilateral and controlateral region or a regional functional reorganisa- tion creating "an unstable relationship between excitatory and inhibitory influences". ${ }^{35}$

All these considerations seems to demonstrate that a better knowledge of the interictal $\mathrm{rCBF}$ and metabolic activation pattern of patients suffering from partial complex seizures should be relevant for clinical practice and physiopathological understanding of the epileptic phenomena.

\section{References}

1 Ingvar DH. Regional CBF in focal cortical epilepsy. Stroke 1973;4:359-60.

2 Hougaard K, Oikawa T, Sveinsdottir E, Skonhoj E, Ingvar DH, Lassen A. Regional cerebral blood flow in focal cortical epilepsy. Arch Neurol 1976;33:527-35.

3 Engel J Jr, Kuhl DE, Phelps ME. Patterns of ictal and interictal local cerebral metabolic rate studied in man with positron computed tomography. Advances in Epileptology. XIIIth Epilepsy International Symposium. New York: Raven Press, 1982:145-9.

4 Bernardi S, Gallhofer B, Trimble MR, Frackoniak RS, Wise RJS, Jones T. An inter-ictal study of partial epilepsy using the oxygen-15 inhalation technique and positron emission tomography with special reference to psychosis. In: BaldyMoulinier M, Ingvar DH, Meldrum BS, eds. Cerebral Blood Flow, Metabolism and Epilepsy, London: J Libbey Eurotext 1983:44-50.

5 Kuhl D, Engel J Jr, Phelps ME, Selin C. Epileptic pattern of local cerebral metabolism and perfusion in human, determined by emission computed tomography of 18FDG and 13NH3. Ann Neurol 1980;3:348-60.

6 Franck G, Sadzot B, Maquet P, et al. Etude chez l'homme par tomographie par emission de positons du metabolisme et du debit sanguin cerebral dans les epilepsies partielles complexes et dans differents etats de mal. Rev Electroencephalogy Neurophysiol Clin 1986;4:199-216.

7 Theodore WH, Porter RJ, Di Chiro G, Satos S. Correlation of positron emission tomography and electro-encephalography in patients with complex partial seizures. In: Baldy-Moulinier $\mathbf{M}$, Ingvar DH, Meldrum BS, eds. Cerebral Blood Flow, Metabolism and Epilepsy. London: J Libbey Eurotext 1983:71-5.

8 Engel J Jr, Kuhl DE, Phelps ME, Mazziotta JC. Interictal cerebral glucose metabolism in partial epilepsy and its relation to EEG changes. Ann Neurol 1982b;12:510-17.

9 Yamamoto YL, Ochs R, Gloor P, et al. Pattern of rCBF and focal energy metabolism changes in to electroencephalographic abnormalities in the inter-ictal of partial epilepsy. In: BaldyMoulinier M, Ingvar DH, Meldrum BS, eds. Cerebral Blood Flow, Metabolism and Epilepsy. London: J Libbey Eurotext 1983:51-62.

10 Lavy S, Melamed E, Portnoy Z, Carmon A. Interictal regional cerebral blood flow in patients with partial seizures. Neurology 1976;26:418-22.

11 Baldy-Moulinier M, Valmier J, Touchon J, Billiard M, Besset A, Cadilhac J. Débits cérébraux régionaux diminués en période intercritique dans l'épilepsie du lobe temporal. Rev Neurol (Paris) 1985;141:18-27.

12 Bonte FJ, Stokely EM, Devous MD, Homan RW. Single photon tomographic study of regional cerebral blood flow in epilepsy. Arch Neurol 1983;140:267-70.

13 Rosadini G, Ferillo F, Rodriguez G, Sannita WG, Arvigo F. rCBF and quantitative EEG correlations in epileptic patients In: Baldy-Moulinier M, Ingvar DH, Meldrum BS, eds. Cerebral Blood Flow, Metabolism and Epilepsy. London: J Libbey Eurotext 1983:26-32. 
14 Stefan H, Kuhnen C, Biersack HJ, Reichmann K. Initial experience with HM-PAO single photon emission computed tomography in patients with focal epilepsy. Epilepsy Res 1987;1:134-8.

15 Touchon J, Valmier J, Baldy-Moulinier M. Regional cerebral blood flow in temporal lobe epilepsy: inter-ictal studies. In: Baldy-Moulinier M, Ingvar DH, Meldrum BS, eds. Cerebral Blood Flow, Metabolism and Epilepsy. London: J Libbey Eurotext 1983:33-8.

16 Touchon J, Valmier J, Baldy-Moulinier M, Cadilhac J. Regional cerebral blood flow during inter-ictal state: differences between temporal lobe epilepsy and primary generalized epilepsy. Eur Neurol 1986;25:43-52.

17 Theodore WH, Fishbein D, Deizt M, Baldwin P. Complex partial seizures: cerebellar metabolism. Epilepsia 1987;28:319-23.

18 Valmier J, Touchon J, Daures P, Zanca M, Baldy-Moulinier M. Correlations between cerebral blood flow variations and clinical parameters in temporal lobe epilepsy. An interictal study. $J$ Neurol Neurosurg Psychiatry 1987;50:1306-11.

19 Theodore WH, Dichiro G, Margolin R, Fishbein D, Porter RJ, Brooks RA. Barbiturates reduce human cerebral metabolism. Neurology 1986;36:60-4.

20 Theodore WH, Bairamian D, Newmark ME, Dichiro G, Porter RJ, Larson S, Fishbein D. Effect of phenytoin on human cerebral glucose metabolism. J Cerebr Blood Flow 1987;6: 315-20.

21 Sakai F, Meyer JS, Naritomi H, Hsu MC. Regional cerebral blood flow and EEG in patients with epilepsy. Arch Neurol 1978; 35:648-57.

22 Commission on classification and terminology of the International League Against Epilepsy. Epilepsia 1986;26:268-78.

23 Meric P, Seylaz J, Correze JL, Luft A, Mamo H. Measurement of regional blood flow by intravenous injection of 133 xenon. Med Prog Technol 1979;3:53-63.

24 Phelps ME, Mazziotta JC, Kuhl DE, et al. Tomographic mapping of human cerebral metabolism: visual stimulation and deprivation. Neurology 1981;31:517-29.

25 Deutsch G, Papanicolaou AC, Eisenberg HM, Loring DW, Levin HS. CBF gradient changes elicited by visual stimulation and visual memory tasks. Neuropsychologia 24, 1986;2:283-7.
26 Naquet R, Menini Ch, Cepada C. Mechanism of appearance of paroxysmal responses induced by intermittent light stimulation. In: Akimoto $\mathbf{H}$, Kazamatsuri H, Seino M, Ward AA, eds. Advances in Epileptology (XIIth Symposium) 1982:249-54.

27 Ingvar DH, Risberg J. Increase in regional cerebral blood flow during mental effort in normals and patients with focal brain disorders. Exp Brain Res 1967;3:195-211.

28 Deutsch G, Papanicolaou AC, Eisenberg HM. CBF during tasks intended to differentially activate the cerebral hemispheres: New normative data and preliminary application in recovering stroke patients. J Cerebr Blood Flow Metab 1987;7 Suppl.1:306.

29 Viader F, Cambier J, Luft A, Ponsin JC, Meric P, Mamo H. Etude du debit sanguin cerebral par injection intraveineuse de Xénon 133 lors de lésions thalamiques et juxtathalamiques. Rev Neurol (Paris) 1987;143:729-36.

30 Oikawa T, Kanaya H. Regional cerebral blood flow activated with photic stimulation in focal cortical epilepsy. In: BaldyMoulinier M, Ingvar DH, Meldrum BS, eds. Cerebral Blood Flow, Metabolism and Epilepsy. London: J Libbey Eurotext 1983:63-70.

31 Engel J Jr, Brown WJ, Kuhl DE, Phelps ME, Mazziotta JC, Crandall PH. Pathological findings underlying focal temporal lobe hypo-metabolism in partial epilepsy. Ann Neurol 1982c; 12:518-27.

32 Lerner-Natoli M, Le Poncin-Laffitte M, Rondouin G, Rapin J, Baldy-Moulinier M. Simultaneous determination of local cerebral blood flow and metabolism in the different stages of amygdaloid kindling. In: Baldy-Moulinier $\mathbf{M}$, Ingvar $\mathbf{D H}$, Meldrum BS, eds. Cerebral Blood Flow, Metabolism and Epilepsy. London: J Libbey Eurotext 1983:105-11.

33 Racine RJ, Tuff L, Zaide J. Kindling unit discharge patterns and neural plasticity. In: Wada JA, ed. Kindling. New York: Raven Press, 1976:19-39.

34 Crandall JE, Bernstein JJ, Boast CA, Zornetzer SF. Kindling in the rat hippocampus: absence of dendritic alterations. Behav Neurol Biol 1979;40:881-3.

35 Engel J Jr, Babb TL, Phelps ME. Contribution of positron emission tomography to understanding mechanisms of epilepsy. Fundamental Mechanisms of Human Brain Function. In: Engel J Jr, et al, eds. New York: Raven Press, 1987:209-13. 